\title{
Research Article Performance Investigation of CMM Measurement Quality Using Flick Standard
}

\author{
Salah H. R. Ali \\ Engineering and Surface Metrology Department, National Institute for Standards (NIS), Giza 12211-136, Egypt \\ Correspondence should be addressed to Salah H. R. Ali; salahali20@yahoo.com
}

Received 6 May 2014; Accepted 17 June 2014; Published 17 July 2014

Academic Editor: Shey-Huei Sheu

Copyright (C) 2014 Salah H. R. Ali. This is an open access article distributed under the Creative Commons Attribution License, which permits unrestricted use, distribution, and reproduction in any medium, provided the original work is properly cited.

Quality of coordinate measuring machine (CMM) in dimension and form metrology is designed and performed at the NIS. The experimental investigation of CMM performance is developed by using reference Flick standard. The measurement errors of corresponding geometric evaluation algorithm (LSQ, ME, MC, and MI) and probe scanning speed (1, 2, 3, 4, and $5 \mathrm{~mm} / \mathrm{s}$ ) are obtained through repeated arrangement, comparison, and judgment. The experimental results show that the roundness error deviation can be evaluated effectively and exactly for CMM performance by using Flick standard. Some of influencing quantities for diameter and roundness form errors may dominate the results at all fitting algorithms under certain circumstances. It can be shown that the $2 \mathrm{~mm} / \mathrm{s}$ probe speed gives smaller roundness error than $1,3,4$, and $5 \mathrm{~mm} / \mathrm{s}$ within $0.2: 0.3 \mu \mathrm{m}$. It ensures that measurement at $2 \mathrm{~mm} / \mathrm{s}$ is the best case to satisfy the high level of accuracy in the certain condition. Using Flick standard as a quality evaluation tool noted a high precision incremental in diameter and roundness form indication. This means a better transfer stability of CMM quality could be significantly improved. Moreover, some error formulae of data sets have been postulated to correlate the diameter and roundness measurements within the application range. Uncertainty resulting from CMM and environmental temperature has been evaluated and confirmed the quality degree of confidence in the proposed performance investigation.

\section{Introduction}

The advanced electromechanical systems like coordinate measuring machine (CMM) is one of the most diversified fields of mechanical engineering due to the promising technology cooperation with modern industrial strategies. CMM is generally better optimized in microcoordinate metrology. Microcoordinate metrology is an important branch of quality assurance. CMM is typically numerical control system that can be used for dimensional inspection of complex 3D geometry product surfaces. Surface quality is an important parameter in the modern manufacturing, aerospace, and automotive. The influence of dimensional and geometrical form errors is one of the most issues of interest regarding the manufacturing accuracy and surfaces quality. Out of tolerance can produces number of problems like vibration, wear, and noise $[1,2]$. Studying the influence of the geometric fitting algorithms and probe scanning speeds on the measurement error can be an interesting topic for a future research, especially with the growing use of CMM machines [2-5]. In addition, the development of a new CMM machine with accuracy less than a nanometer is necessary, because it is close to the industrial actual needs. For these reasons, most available verification and calibration of CMM requires reference standards artifacts. Flick standard is embodiment of outer surface. New published work in parallel with my research confirmed that the Flick standard is a suitable tool used to calibrate the spindle motion error and the probe which equips cylindrical measuring machines to ensure such a level of uncertainty, both stability and performance [5]. The resultant measurement quality of CMM is limited by deviation and some uncertainties due to different factors. The measurement deviations in CMM metrology can be related to the operator performance quality, environmental interaction, and CMM performance accuracy. It can be assumed that some important factors such as operator behavior and CMM software accuracy have effective reaction on the measurement quality. Uncertainty in measurement is the most important 
concept in roundness metrology according to the GUM and attracts wide attention in the world to confirm the confidence in measurement result [6].

In this paper, measurements for transverse circle location of certified Flick standard have been carried out. The measurement results of dimension and geometrical form at different CMM strategies have been studied. The influence of geometric fitting algorithms equipped with probe scanning speeds as metrological parameters on both diameter $(D)$ and roundness form errors (RON) is investigated and discussed. The modifications and analysis of software are employed experimentally. The statistical study based on design of experiment was accomplished in order to evaluate the measurement result and estimate the expanded uncertainties. Therefore, the main objective of this research is projected to study the influence of four fitting algorithms through five different probe scanning speeds for transverse circle location of carrying out signals to:

(a) develop the CMM software using closed loop control for increase the accuracy and precision of new machines,

(b) increase CMM operator skills and reduce the operation lost time and cost, to avoid processing mistakes of software strategic applications,

(c) determine and analyze the relative deviation errors in measurement,

(d) minimize the size of uncertainty in measurement.

\section{Experimental Work}

The experiment in this paper is designed and performed within the research plan of the Engineering and Surface Metrology Department at NIS. The experimental investigations including measurement procedures are designed to study the effect of geometric fitting algorithm and probe scanning speed on CMM measurement. This plan has been done through two main stages. The first stage is verification of CMM probing system. The main stage in the experiments is made to verify the CMM machine in measurement quality. This second stage based on the measurement of the diameter and roundness of the Flick standard at different strategies in measurement. The dynamic influences of geometric fitting algorithms and probe canning speeds strategies on diameter and roundness deviations have been studied using CMM.

2.1. Verification of CMM Probing System. Dynamic verification of probing system is the very important recommendation task for an acceptance before study CMM performance accuracy $[7,8]$. The standard verification method of both probing error and scanning probing error using reference sphere is used. To determine the probing error, it must be probed twenty five recommended points on the reference test sphere surface. To determine the scanning probing error, it must scan four recommended scanning lines on the surface of test sphere and compute. The Gaussian center point of the sphere using all measured points of all four scan lines. Before making measurements with the CMM in the cylindrical
TABLE 1: Output verification data of CMM probes and sphere.

\begin{tabular}{lcc}
\hline CMM element & Measured value, $\mathrm{mm}$ & $\mathrm{SD}, \mathrm{mm}$ \\
\hline Master probe & $R=3.9999$ & 0.0002 \\
Reference sphere & $R=14.9942$ & 0.0002 \\
Used stylus probe & $R=1.4990, L=33.5$ & 0.0002 \\
With Al. extension & $L=100$ & \\
Step width & 1.3861 & \\
Number of probe points & 104 points & \\
\hline
\end{tabular}

feature of Flick standard, the CMM was verified using master probe to evaluate standard sphere and using standard sphere to evaluate used probe [9]. The standard deviation (SD) of program output result in the CMM verification test conditions is presented in Table 1. The CMM has limited specific values as follows:

$$
\begin{gathered}
\mathrm{MPE}=A+\frac{L}{K}, \mu \mathrm{m}, \\
\mathrm{MPE}_{P}=1.00 \mu \mathrm{m} ; \\
\operatorname{MPET}_{i j}=1.90 \mu \mathrm{m},
\end{gathered}
$$

where MPE is the maximum permissible measurement error, $A$ is the constant machine uncertainty equal to $0.9 \mu \mathrm{m}, K$ is the length constant or slope of line equal to $350, L$ is the length measurement in $\mathrm{mm}, \mathrm{MPE}_{P}$ is the maximum permissible probing error, and $\mathrm{MPET}_{i j}$ is the maximum permissible error when measuring a part by using scanning mode which is called maximum permissible scanning probing error.

2.2. Flick Standard. The best method of dynamic verification is made through the use of a high precision Flick standard in roundness Talyrond machines. Existing outer surface of Flick standard is only one applicable embodiment type of sensitivity verification for dimensional and geometrical form. Flick standard is a cylindrical artifact with a known nominally one flat face through the outer perimeter. Flick standard have some major disadvantages like a small dynamical contact for larger wave numbers [10]. The amplitude of signals for a typical Flick with a cylinder diameter of about $44 \mathrm{~mm}$ and a deepness of the flattening of $(294.9: 283.3) \mu \mathrm{m}$ has been measured; see Figure 1. While the measured signal to noise ratio is actually low for reference standard Flicks, therefore the author predicted that the use of Flick standard will may be a new suitable tool for verification method of CMM measurement quality.

The CMM output significant contributions from larger wave numbers than 25 UPR (undulation per revolution) are demonstrated in Figure 2. The output result has been performed in an appropriate measurement range for the diameter and roundness form deviations. But the calibration result depends on the individual wave amplitudes. The output signal to noise ratio is quite low for Flick, because the full measured signal is carried by a single wave number.

2.3. CMM Measurement Procedures. The measurements have been carried out at the same transverse section on the outer 


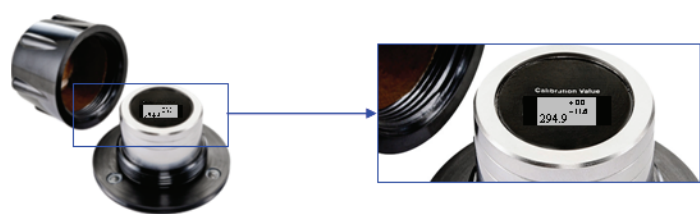

FIGURE 1: Flick standard reference.

surface of the Flick standard at location of $18 \mathrm{~mm}$ from the top to detect any errors of the surface. The measured sample errors were obtained for five probe scanning speeds $1,2,3,4$, and $5 \mathrm{~mm} / \mathrm{s}$ during $360^{\circ}$ angle range trace of the Flick standard, respectively, while CMM traveling speed was constant at $70 \mathrm{~mm} / \mathrm{s}$ and the number of scan fitting points also was constant with about $104 \pm 2$ points during measurement tests at temperature condition of $20 \pm 0.5^{\circ} \mathrm{C}$. Each measurement point has 10 times repetitions for the same transverse circle $(x, y$, and $z$ ) positions. The feature of roundness measurement has been determined at each probe scanning speed, where the CMM PRISMO navigator has been selected corresponding to evaluation fitting algorithms. Four main geometric fitting algorithms are recommended in CMM measurement for cylindrical parts, LSQ, ME, MC, and MI, where LSQ means least square fitting algorithm, ME means minimum element fitting algorithm, MC is minimum circumscribed fitting algorithm, and MI means maximum inscribed fitting algorithm. Determination of measured deviation errors have included 200 experimental measuring tests to differentiate between evaluation qualities of different measurement strategies. The diameter and roundness deviation errors of corresponding evaluation algorithm at different scanning speeds are obtained through comparison, judgment, and repeated arrangement. However, a question arises, which algorithm is suitable to be chosen and what criterion should be taken at which probe scanning speed.

\section{Measurement Results and Discussion}

The distribution density of measured points of both diameter and roundness variation is presented in Figures 3, 5, 7, 9, 11, 13,15 , and 17. The errors' average of results obtained for both diameter and roundness variation are reduced and presented in a more practical and explicit form in Figures 4, 6, 8, 10, $12,14,16$, and 18 . The diameter and roundness error results as functions of the probe scanning speed and fitting algorithm are given as follows.

3.1. Least Square Fitting Technique. The results in Figure 3 present the distribution density of measured points for diameter error of ten reputed test results for Flick transverse circle using LSQ fitting algorithm at different probe scanning speeds. Figure 4 shows the average variation of diameter error for different probe scanning speeds using LSQ fitting algorithm. Analysis of the fifty given results indicates that:

(i) detection LSQ fitting algorithm at probe speed of $1 \mathrm{~mm} / \mathrm{s}$ measurements has a diameter error range of $0.2 \mu \mathrm{m}$ from $43.9705 \mathrm{~mm}$ to $43.9703 \mathrm{~mm}$, while measurements at $2 \mathrm{~mm} / \mathrm{s}$ have diameter error limits of 43.9704 and $43.9703 \mathrm{~mm}$ with an error range of $0.1 \mu \mathrm{m}$, while the error ranges at 3,4 , and $5 \mathrm{~mm} / \mathrm{s}$ measurements became stable within the same value of $0.1 \mu \mathrm{m}$;

(ii) according to the application of the LSQ fitting technique to all measuring speeds, the evaluated difference of average error between probe speeds as representing values to the scanning speed quality has 0.1 and $0.2 \mu \mathrm{m}$ for 1,2 , and $3 \mathrm{~mm} / \mathrm{s}(43.9703 \mathrm{~mm})$ and $4 \mathrm{~mm} / \mathrm{s}(43.9702 \mathrm{~mm})$ and $5 \mathrm{~mm} / \mathrm{s}(43.9701 \mathrm{~mm})$, respectively;

(iii) measurements at $4 \mathrm{~mm} / \mathrm{s}$ have low diameter error for the LSQ fitting algorithm, while at $5 \mathrm{~mm} / \mathrm{s}$ have the lowest diameter error.

The presentation results in Figure 5 show the distribution density of measured points for roundness error of ten reputed test results for Flick transverse circle using LSQ fitting algorithm at different probe scanning speeds. Figure 6 shows the average variation of roundness error for different probe scanning speeds using LSQ fitting algorithm. The result analysis of the fifty tests indicates that:

(i) roundness measurements of LSQ algorithm at $2 \mathrm{~mm} / \mathrm{s}$ have a minimum error of $0.2 \mu \mathrm{m}$ and maximum error of $0.5 \mu \mathrm{m}$ at $5 \mathrm{~mm} / \mathrm{s}$;

(ii) according to the application of the LSQ fitting technique to all measuring speeds, the evaluated difference of average error between probe speeds as representing values to the scanning speed quality has 0.3 for 1 and $4 \mathrm{~mm} / \mathrm{s}(288.8 \mu \mathrm{m})$ and $2 \mathrm{~mm} / \mathrm{s}$ $(288.5 \mu \mathrm{m})$ and at $3 \mathrm{~mm} / \mathrm{s}(288.9 \mu \mathrm{m})$ and $(288.7 \mu \mathrm{m})$ at $5 \mathrm{~mm} / \mathrm{s}$;

(iii) the value of roundness measurement errors for $2 \mathrm{~mm} / \mathrm{s}$ has the lowest significant variation compared to all other probe speeds.

3.2. Minimum Element Fitting Technique. Figure 7 shows the density of measured points for diameter error of ten reputed test results for Flick transverse circle using ME fitting algorithm at different probe scanning speeds. Figure 8 shows the average variation of diameter error for different probe scanning speeds using ME fitting algorithm. Analysis of the fifty given results indicates that:

(i) detection ME fitting algorithm at probe speed of $1 \mathrm{~mm} / \mathrm{s}$ measurements has a diameter error range of $0.5 \mu \mathrm{m}$ from $43.9868 \mathrm{~mm}$ to $43.9863 \mathrm{~mm}$, while measurements at $2 \mathrm{~mm} / \mathrm{s}$ have diameter error limits of 43.9865 and $43.9864 \mathrm{~mm}$ with an error range of $0.1 \mu \mathrm{m}$. While the error ranges at $3 \mathrm{~mm} / \mathrm{s}$ measurements have the highest diameter error range of $0.6 \mu \mathrm{m}$, measurements at $2 \mathrm{~mm} / \mathrm{s}$ have the lowest diameter error for the ME fitting algorithm, while at $1 \mathrm{~mm} / \mathrm{s}$ they have the highest diameter error of $0.5 \mu \mathrm{m}$; 


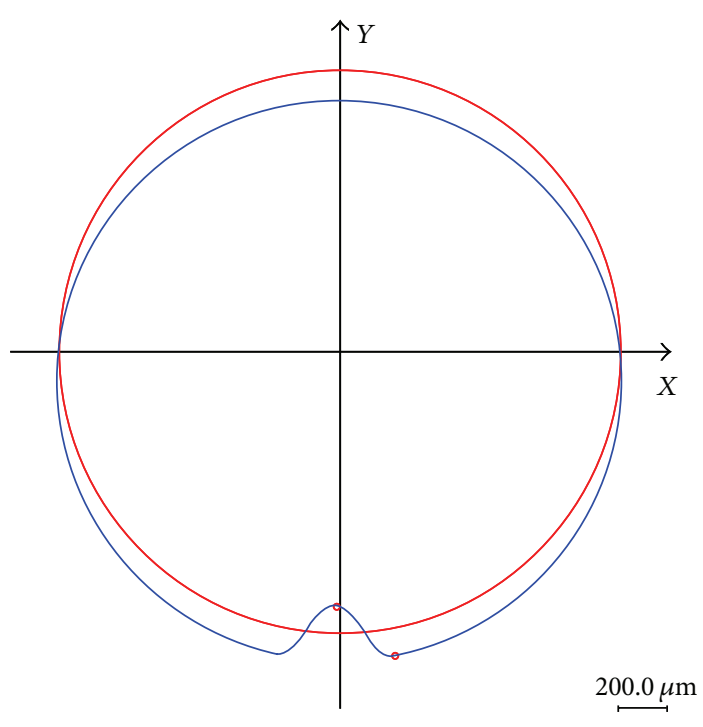

(a) Outer roundness form profile

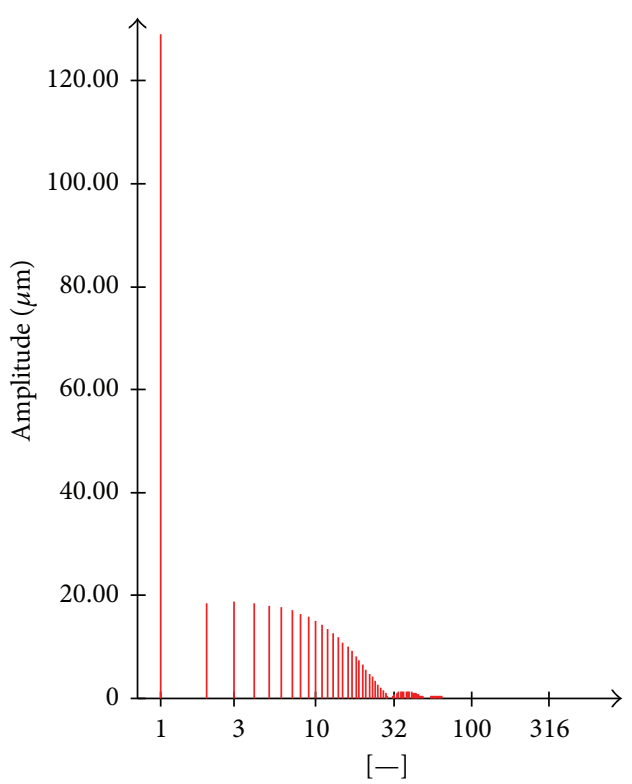

(b) Spectrum amplitude at max frequency $51 \mathrm{~Hz}$

FIGURE 2: Typical result of a Flick standard reference at scanning speed of $1 \mathrm{~mm} / \mathrm{sec}$ at LSQ fitting algorithm and Gaussian filter using CMM with magnification factor 100 .

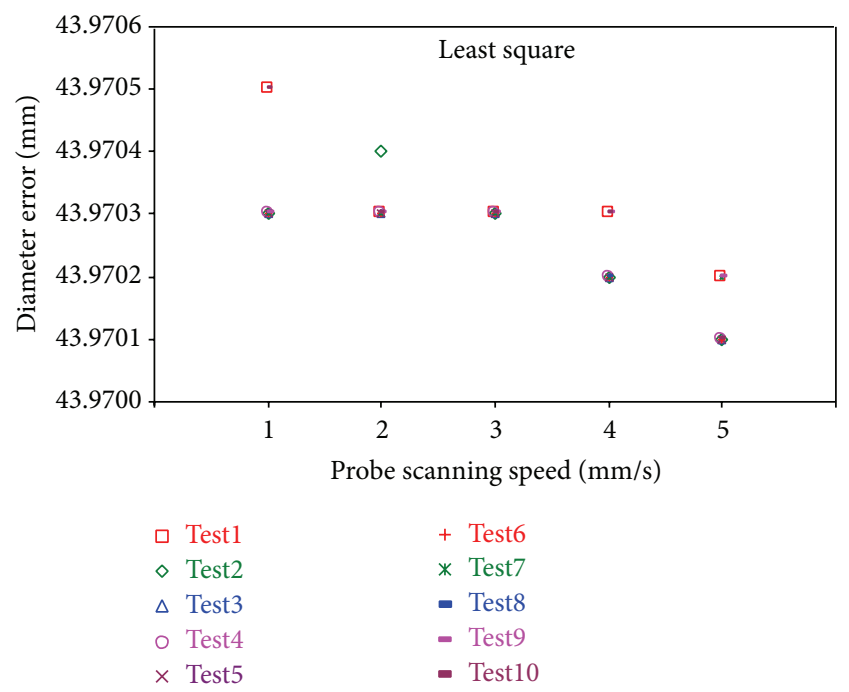

FIGURE 3: Diameter errors variation of LSQ fitting algorithm at different probe scanning speeds.

(ii) according to the application of the ME fitting algorithm to all measuring speeds, the evaluated difference of average error between probe speeds as representing values to the scanning speed quality has 0.1 and $0.6 \mu \mathrm{m}$ for 1,3 , and $4 \mathrm{~mm} / \mathrm{s}(43.9865 \mathrm{~mm})$ and at 2 and $5 \mathrm{~mm} / \mathrm{s}(43.9864 \mathrm{~mm})$, respectively;

(iii) the measuring error range has the lowest significant variation at $2 \mathrm{~mm} / \mathrm{s}$ compared to $1,3,4$, and $5 \mathrm{~mm} / \mathrm{s}$ testing speed, which may be due to probe response at resonance traveling speed.

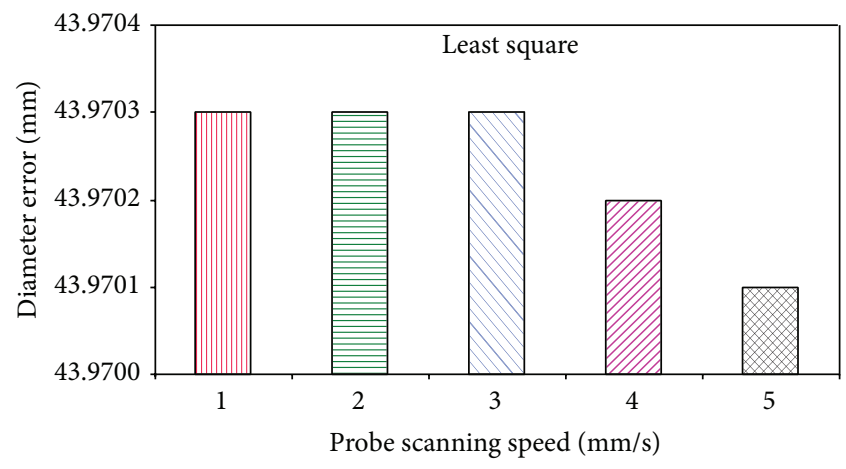

FIGURE 4: Measuring errors average of diameter at different probe scanning speeds with LSQ fitting algorithm.

The presented results in Figure 9 show the distribution density of measured points for roundness error of ten reputed test results for Flick transverse circle using ME fitting algorithm at different probe scanning speeds. Figure 10 shows the average variation of roundness error for different probe scanning speeds using ME fitting algorithm. Analysis of the given result indicates that:

(i) roundness measurements of ME algorithm at $2 \mathrm{~mm} / \mathrm{s}$ have a minimum average error of $285.7 \mu \mathrm{m}$ relative to all other probe speeds;

(ii) according to the application of the ME fitting technique to all measuring speeds, the evaluated difference of average error between probe speeds as representing values to the scanning speed quality has $(286.0 \mu \mathrm{m})$ for $1,3,4$, and $5 \mathrm{~mm} / \mathrm{s}$; 


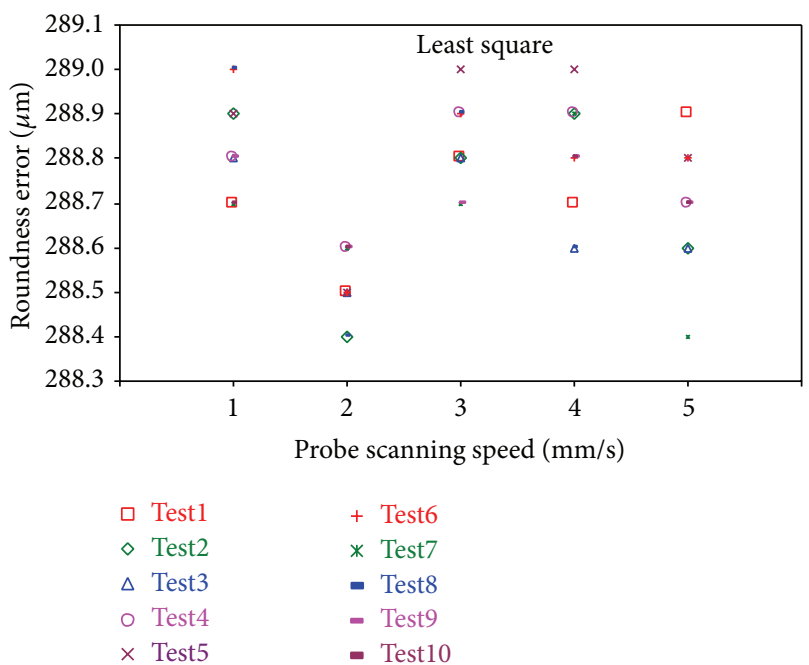

FIGURE 5: Roundness errors variation of LSQ fitting algorithm at different probe scanning speeds.

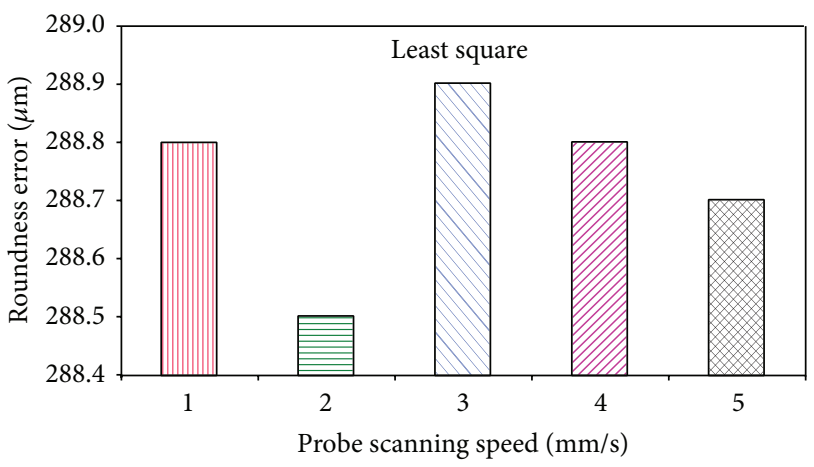

FigURE 6: Measuring errors average of roundness at different probe scanning speeds with LSQ fitting algorithm.

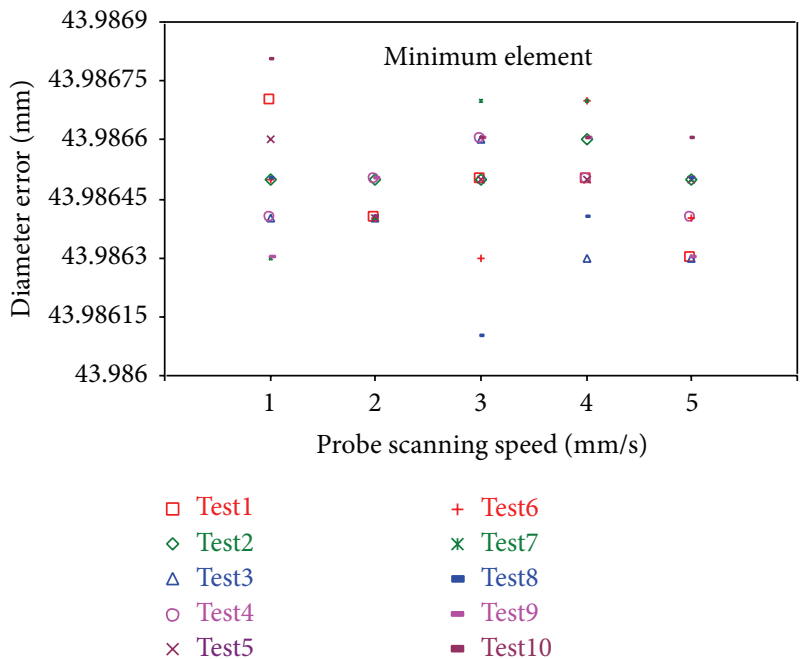

FIgURE 7: Diameter errors variation of ME fitting algorithm at different probe scanning speeds.

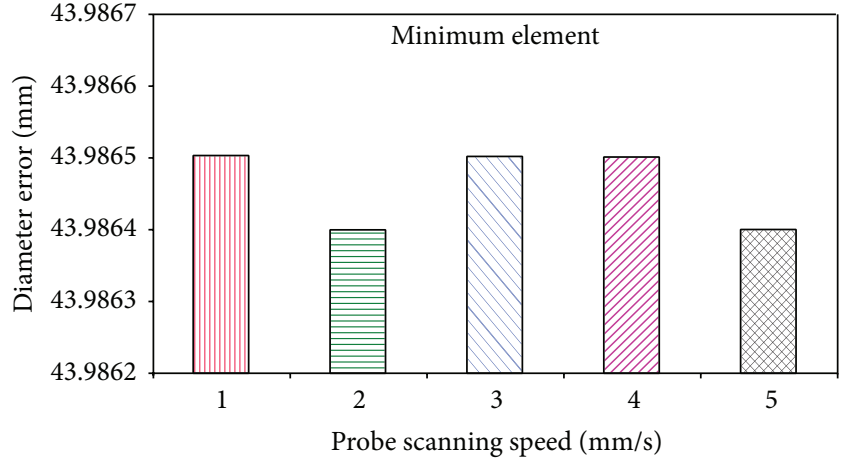

FIGURE 8: Measuring errors average of diameter at different probe scanning speeds with ME fitting algorithm.

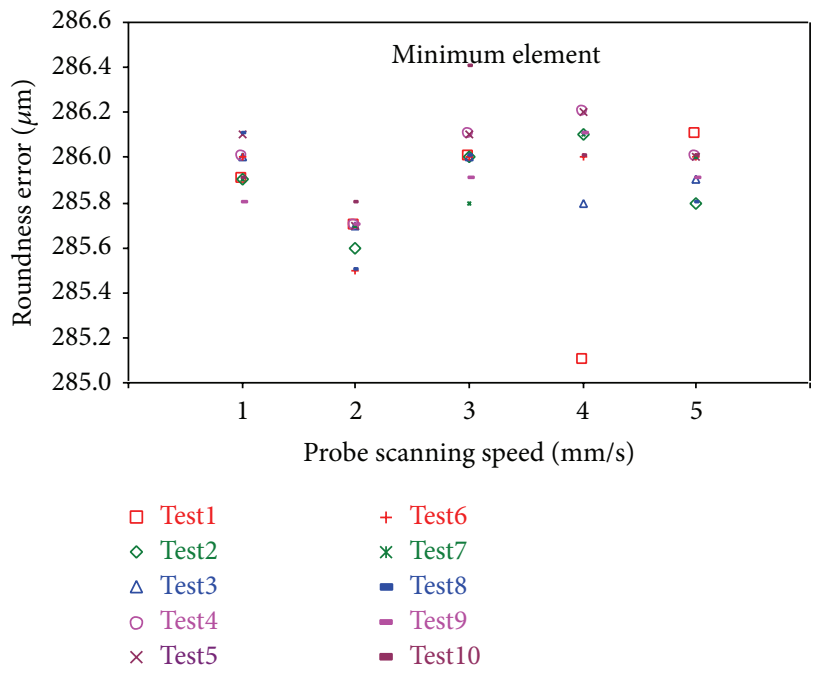

FIGURE 9: Roundness errors variation of ME fitting algorithm at different probe scanning speeds.

(iii) the value of roundness measurement errors for $2 \mathrm{~mm} / \mathrm{s}$ has the lowest significant variation of $0.3 \mu \mathrm{m}$ compared to all other probe scanning speeds.

3.3. Minimum Circumscribed Fitting Technique. The results in Figure 11 indicate the density of measured points for diameter error of ten reputed test results for Flick transverse circle using MC fitting algorithm at different probe scanning speeds. Figure 12 shows the average variation of diameter error for different probe scanning speeds using MC fitting algorithm. Analysis of the fifty given results indicates that:

(i) detection MC fitting technique at probe speed of $1 \mathrm{~mm} / \mathrm{s}$ measurements has a diameter error range of $0.3 \mu \mathrm{m}$ from $43.9907 \mathrm{~mm}$ to $43.9904 \mathrm{~mm}$, while measurements at $2 \mathrm{~mm} / \mathrm{s}$ have diameter error limits of 43.9907 and $43.9905 \mathrm{~mm}$ with an error range of $0.2 \mu \mathrm{m}$. While the error ranges at 3 and $5 \mathrm{~mm} / \mathrm{s}$ measurements have the lowest diameter variation error range of $0.1 \mu \mathrm{m}$, measurements at $5 \mathrm{~mm} / \mathrm{s}$ have 


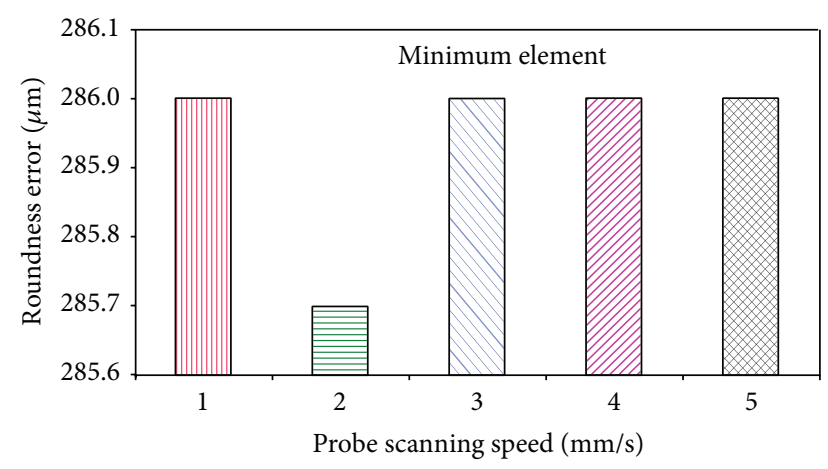

FIGURE 10: Measuring errors average of roundness at different probe scanning speeds with ME fitting algorithm.

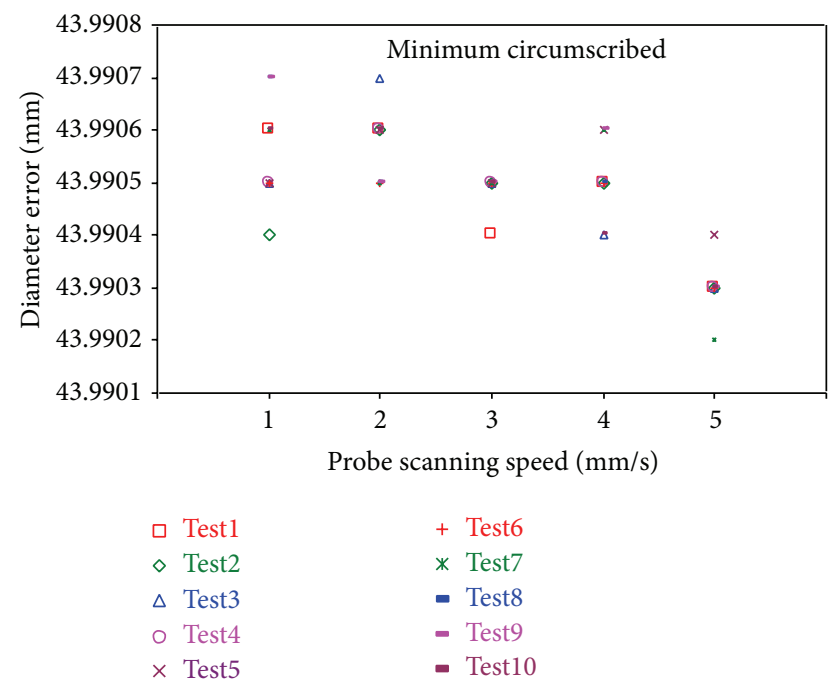

FIGURE 11: Diameter errors variation of MC fitting algorithm at different probe scanning speeds.

the lowest average diameter error of $43.9903 \mathrm{~mm}$ for the ME fitting algorithm;

(ii) according to the application of the MC fitting algorithm to all measuring speeds, the evaluated difference of average error between probe speeds as representing values to the scanning speed quality has 0.1 and $0.3 \mu \mathrm{m}$ for 1 and $2 \mathrm{~mm} / \mathrm{s}(43.9906 \mathrm{~mm})$, for 3 and $4 \mathrm{~mm} / \mathrm{s}(43.9905 \mathrm{~mm})$, and $5 \mathrm{~mm} / \mathrm{s}(43.9903 \mathrm{~mm})$, respectively.

(iii) the measuring error range has the lowest significant variation at $3 \mathrm{~mm} / \mathrm{s}$ compared to $1 \mathrm{~mm} / \mathrm{s}$ testing speed, which may be due to probe response at resonance traveling speed at MC algorithm design.

The presentation results in Figure 13 show the density of measured points for roundness error of ten reputed test results for Flick transverse circle using MC fitting algorithm at different probe scanning speeds. Figure 14 shows the average variation of roundness error for different probe scanning speeds using MC fitting technique. The result analysis of the fifty tests indicates that:

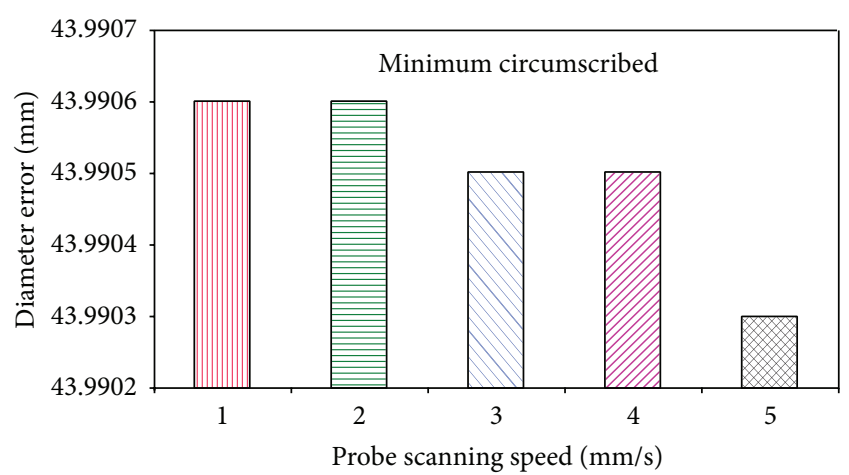

FIGURE 12: Measuring errors average of diameter at different probe scanning speeds with MC fitting algorithm.

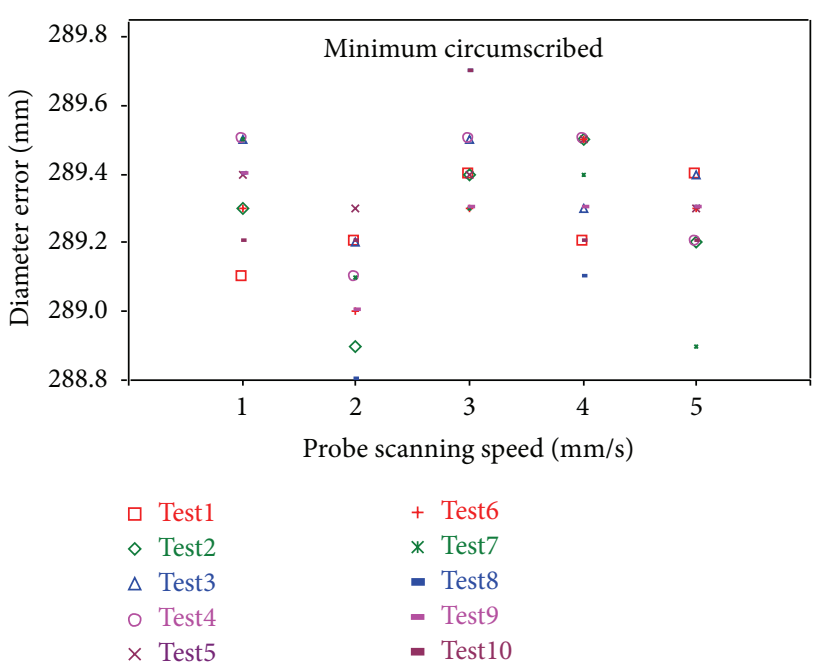

FIGURE 13: Roundness errors variation of MC fitting algorithm at different probe scanning speeds.

(i) roundness measurements of $\mathrm{MC}$ algorithm at 1, 3, and $4 \mathrm{~mm} / \mathrm{s}$ have a minimum error of $0.4 \mu \mathrm{m}$ and maximum error of $0.5 \mu \mathrm{m}$ at 2 and $5 \mathrm{~mm} / \mathrm{s}$;

(ii) according to the application of the MC fitting technique to all measuring speeds, the evaluated difference of average error between probe speeds as representing values to the scanning speed quality has $0.4 \mu \mathrm{m}$ for 1 and $4 \mathrm{~mm} / \mathrm{s}(289.4 \mu \mathrm{m})$ and $2 \mathrm{~mm} / \mathrm{s}$ $(289.1 \mu \mathrm{m})$ and at $3 \mathrm{~mm} / \mathrm{s}(289.5 \mu \mathrm{m})$ and $(289.3 \mu \mathrm{m})$ at $5 \mathrm{~mm} / \mathrm{s}$;

(iii) the value of roundness measurement errors for $2 \mathrm{~mm} / \mathrm{s}$ has the lowest significant variation compared to all other probe scanning speeds.

3.4. Maximum Inscribed Fitting Technique. As in Figure 15, the density of measured points for diameter error of ten reputed test results for Flick transverse circle using MI fitting algorithm at different probe scanning speeds. Figure 16 shows the average variation of diameter error for different probe 


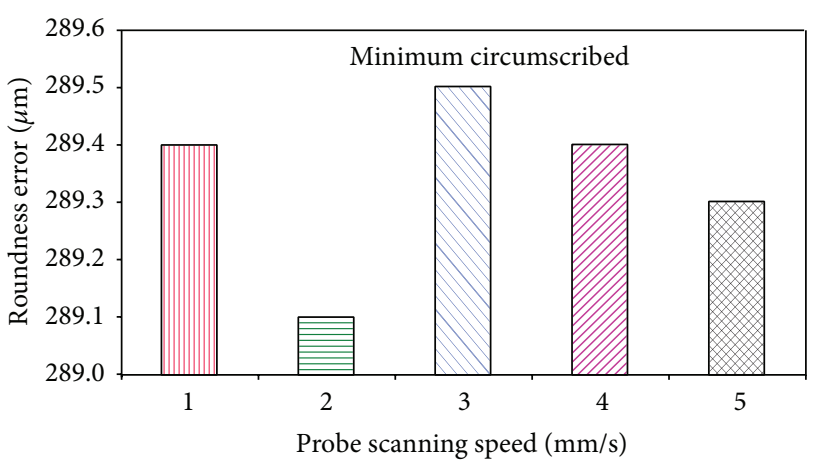

FIGURE 14: Measuring errors average of roundness at different probe scanning speeds with MC fitting algorithm.

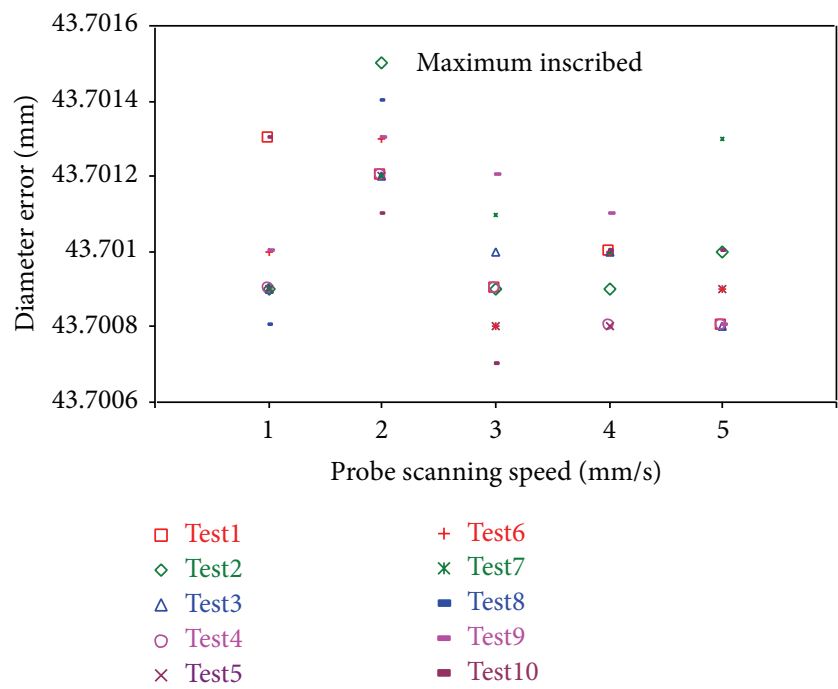

FIGURE 15: Diameter errors variation of MI fitting algorithm at different probe scanning speeds.

scanning speeds using MI fitting algorithm. Analysis of the fifty given results indicates that:

(i) detection MI fitting technique at probe speed of $1 \mathrm{~mm} / \mathrm{s}$ measurements has a diameter error range of $0.5 \mu \mathrm{m}$ from $43.7013 \mathrm{~mm}$ to $43.7008 \mathrm{~mm}$, while measurements at $2 \mathrm{~mm} / \mathrm{s}$ have diameter error limits of 43.7015 and $43.7011 \mathrm{~mm}$ with an error range of $0.4 \mu \mathrm{m}$. While the error ranges at 3 and $5 \mathrm{~mm} / \mathrm{s}$ measurements have the highest diameter error range of $0.5 \mu \mathrm{m}$, measurements at $4 \mathrm{~mm} / \mathrm{s}$ have the lowest diameter error variation of $0.2 \mu \mathrm{m}$ for the MI fitting algorithm;

(ii) according to the application of the MI fitting algorithm to all measuring speeds, the evaluated difference of average error between probe speeds as representing values to the scanning speed quality has 0.5 and $0.2 \mu \mathrm{m}$ for 1 and $4 \mathrm{~mm} / \mathrm{s}(43.7010 \mathrm{~mm})$, for 3 and $5 \mathrm{~mm} / \mathrm{s}(43.9709 \mathrm{~mm})$ and for $2 \mathrm{~mm} / \mathrm{s}$ (43.9713 mm), respectively.

The presented results in Figure 17 present the distribution density of measured points for roundness error

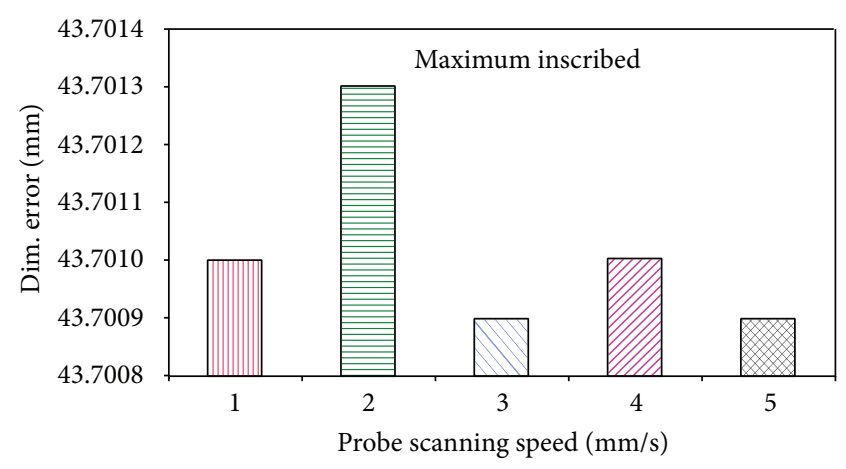

FIGURE 16: Measuring errors average of diameter at different probe scanning speeds with MI fitting algorithm.

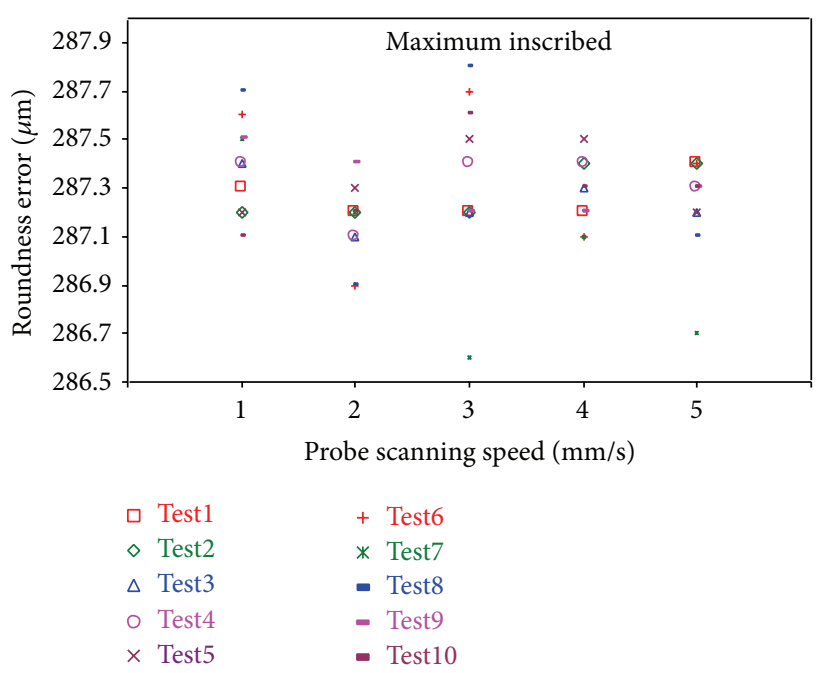

FIGURE 17: Roundness errors variation of MI fitting algorithm at different probe scanning speeds.

of ten reputed test results for Flick transverse circle using MI fitting algorithm at different probe scanning speeds. Figure 18 shows the average variation of roundness error for different probe scanning speeds using MI fitting algorithm. Analysis of the fifty given results indicates that:

(i) roundness measurements of $\mathrm{MI}$ algorithm at $4 \mathrm{~mm} / \mathrm{s}$ have a minimum error of $0.4 \mu \mathrm{m}$ and maximum error of $0.6 \mu \mathrm{m}$ at 1,3 and $5 \mathrm{~mm} / \mathrm{s}$;

(ii) according to the application of the MI fitting technique to all measuring speeds, the evaluated difference of average error between probe speeds as representing values to the scanning speed quality,has $287.3 \mu \mathrm{m}$ at 3 and $4 \mathrm{~mm} / \mathrm{s}$, while at $1 \mathrm{~mm} / \mathrm{s}(287.4 \mu \mathrm{m})$ and $(287.2 \mu \mathrm{m})$ at 2 and $5 \mathrm{~mm} / \mathrm{s}$;

(iii) the value of roundness measurement errors for 2 and $5 \mathrm{~mm} / \mathrm{s}$ has lowest significant average variation compared to other probe speeds. 
TABLE 2: Average variation and standard deviation of Flick diameter (mm).

\begin{tabular}{|c|c|c|c|c|c|c|}
\hline Scanning speed, $\mathrm{mm} / \mathrm{s}$ & LSQ & $\mathrm{ME}$ & $\mathrm{MC}$ & MI & Average of $D$ & $\mathrm{SD}$ \\
\hline 1 & 43.9703 & 43.9865 & 43.9906 & 43.7010 & 43.9121 & 0.1221 \\
\hline 2 & 43.9703 & 43.9864 & 43.9906 & 43.7013 & 43.9122 & 0.1220 \\
\hline 3 & 43.9703 & 43.9865 & 43.9905 & 43.7009 & 43.9121 & 0.1221 \\
\hline 4 & 43.9702 & 43.9865 & 43.9905 & 43.7010 & 43.9121 & 0.1221 \\
\hline 5 & 43.9701 & 43.9864 & 43.9903 & 43.7009 & 43.9119 & 0.1221 \\
\hline Average of $D$ & 43.9702 & 43.9865 & 43.9905 & 43.7010 & 43.9120 & \\
\hline $\mathrm{SD}$ & 0.0001 & 0.0000 & 0.0001 & 0.0001 & & \\
\hline$u_{1}=\mathrm{SD} / \sqrt{n}$ & 0.0001 & 0.0000 & 0.0001 & 0.0001 & & \\
\hline
\end{tabular}

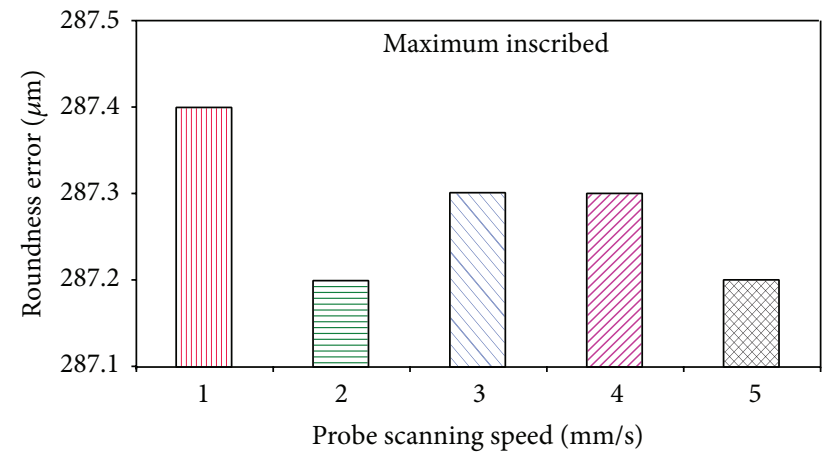

FIGURE 18: Measuring errors average of roundness at different probe scanning speeds with MI fitting algorithm.

\section{Statistical Analysis}

To give more reliable analysis of the experimental data of the influence of fitting algorithm and probe scanning speed on the CMM measurement accuracy should be using statistical tests. Statistical test analysis of diameter and roundness error averages, standard deviation and combined uncertainty $\left(u_{1}\right)$ due to repeatability are calculated. Expanded uncertainty for selected parameters in measurement has been evaluated. The statistical results obtained are reduced and presented in a more practical and explicit error form in Figures 19 and 20. The errors averages in diameter and roundness results as function of the five probe scanning speed using four fitting techniques are given as follows.

4.1. The Error in Diameter Measurement. The error response of diameter variation for Flick standard related to different CMM measurements strategies of different fitting algorithms of probe scanning speeds is indicated in Table 2 and presented in Figure 19. The indicated results include the following:

(i) signal measured for 200 evaluated samples has a global average of Flick diameter of $43.9120 \mathrm{~mm}$. The samples at probe scanning speeds of $1,2,3,4$, and $5 \mathrm{~mm} / \mathrm{s}$ have the roundness averaged values 43.9121, 43.9122, 43.9121, 43.9121, and $43.9119 \mathrm{~mm}$, which correspond to represent $100.0002,100.0005,100.0002$, 100.0002 , and $99.9998 \%$ of the global average, respectively. It ensures that measurements at probe speed
$5 \mathrm{~mm} / \mathrm{s}$ are the suitable case for this work piece Flick to satisfy the high level of accuracy;

(ii) averaged percentage errors as a function of the fitting algorithm response with respect to the global mean value are 100.1325, 100.1697, 100.1788, and 99.5195\%, which are corresponding to LSQ, ME, MC, and MI, respectively. Quality of measurements indicates that MC and ME algorithms have about $0.1788 \%$ and $0.1697 \%$ inaccuracy, while the LSQ and MI algorithms have accurate responses with the error range of $0.1325 \%$ and $-0.4805 \%$, respectively;

(iii) signal measured for evaluated test samples at probe scanning speeds from 1 to $5 \mathrm{~mm} / \mathrm{s}$ (with $1 \mathrm{~mm} / \mathrm{s}$ interval value) has the standard deviation (SD) values of $0.1221,0.1220,0.1221,0.1221$, and $0.1221 \mathrm{~mm}$, respectively. It ensures that measurement at probe speed of $2 \mathrm{~mm} / \mathrm{s}$ is the suitable case for this work piece to satisfy the high level of accuracy;

(iv) the diameter standard deviation has the best significant variation at $2 \mathrm{~mm} / \mathrm{s}$ for all fitting algorithms; this may be due to probe response at resonance traveling speed;

(v) the ME algorithm has the lowest standard deviation average response, while all other algorithms have the same accurate response within the application range.

(vi) the uncertainty due to repeatability in diameter measurement for four fitting algorithms does not exceed 0.0001 ;

(vii) from the data presented in Figure 19, the values have been treated statistically using fit linear regression type to get general formulae of the diameter error in $\mathrm{mm}$ as a function of probe scanning speed $V$ for the different four fitting algorithms as follows:

$$
\begin{aligned}
& \operatorname{RON}_{(\mathrm{MC})}=-1 E-05 V+43.9860 \\
& \mathrm{RON}_{(\mathrm{ME})}=-7 E-05 V+43.9910 \\
& \mathrm{RON}_{(\mathrm{LSQ})}=-5 E-05 V+43.9700 \\
& \operatorname{RON}_{(\mathrm{MI})}=-5 E-05 V+43.7010
\end{aligned}
$$

From the linear regression equations (2), the empirical formulae illustrate that the $\mathrm{ME}$ algorithm has high error 
TABLE 3: Average variation and standard deviation of Flick roundness $(\mu \mathrm{m})$.

\begin{tabular}{|c|c|c|c|c|c|c|}
\hline Scanning speed, $\mathrm{mm} / \mathrm{s}$ & LSQ & ME & $\mathrm{MC}$ & MI & Average of RON & SD \\
\hline 1 & 288.8 & 286.0 & 289.4 & 287.4 & 287.9 & 1.3153 \\
\hline 2 & 288.5 & 285.7 & 289.1 & 287.2 & 287.6 & 1.3065 \\
\hline 3 & 288.9 & 286.0 & 289.5 & 287.3 & 287.9 & 1.3718 \\
\hline 4 & 288.8 & 286.0 & 289.4 & 287.3 & 287.9 & 1.3255 \\
\hline 5 & 288.7 & 286.0 & 289.3 & 287.2 & 287.8 & 1.2903 \\
\hline Average of RON & 288.7 & 285.9 & 289.3 & 287.3 & 287.8 & \\
\hline SD & 0.1356 & 0.1200 & 0.1356 & 0.0748 & & \\
\hline$u_{1}=\mathrm{SD} / \sqrt{n}$ & 0.0606 & 0.0537 & 0.0606 & 0.0335 & & \\
\hline
\end{tabular}

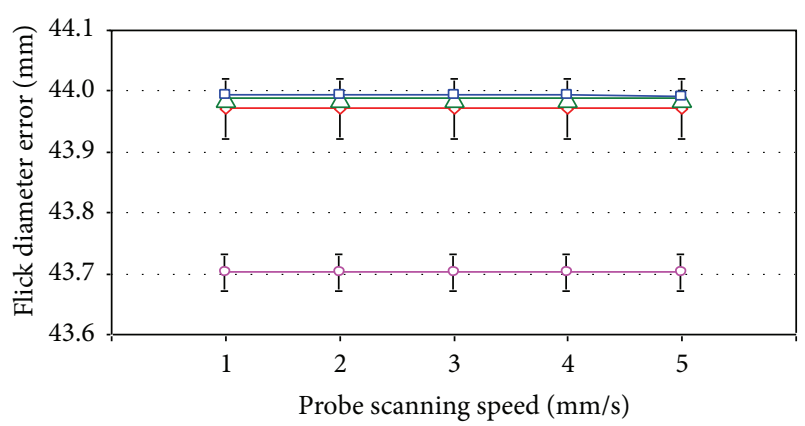

$$
\begin{array}{ll}
\text { Average } & \\
\neg-\mathrm{LSQ} & -\square-\mathrm{MC} \\
\neg-\mathrm{ME} & -\circ \mathrm{MI}
\end{array}
$$

FIGURE 19: Average variation of Flick diameter measurements at different CMM strategies.

potential of $43.991 \mathrm{~mm}$ at sensitivity coefficients of $-7 E-05$ to the probe scanning speed $(V)$, where MI technique has the lowest error potential of $43.701 \mathrm{~mm}$ at sensitivity coefficients of $-5 E-05$ to the probe scanning speed. The LSQ algorithm has an error potential of $43.970 \mathrm{~mm}$ at sensitivity coefficients of $-5 E-05$ to the probe scanning speed. The MC algorithm has an error potential of $43.986 \mathrm{~mm}$ at sensitivity coefficients of $-1 E-05$ to the probe scanning speed.

4.2. The Error in Roundness Measurement. The error response of roundness variation for Flick standard related to different CMM measurements strategies of different fitting algorithms of probe scanning speeds is presented in Table 3 and shown in Figure 20. The statistical results indicate that:

(i) signal measured for 200 evaluated samples has a global average of Flick roundness of $287.8 \mu \mathrm{m}$. The samples at probe scanning speeds of $1,2,3,4$, and $5 \mathrm{~mm} / \mathrm{s}$ have the roundness averaged values 287.9, $287.6,287.9,287.9$, and $287.8 \mu \mathrm{m}$, which correspond to represent 100.04, 99.93, 100.04, 100.04, and 100.00\% of the global average, respectively. It ensures that measurement at probe speed $2 \mathrm{~mm} / \mathrm{s}$ is the suitable case for this work piece Flick to satisfy the high level of accuracy.

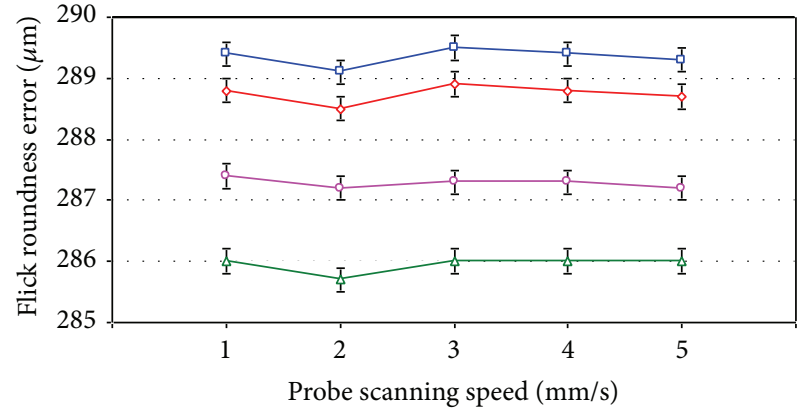

Average

$$
\begin{array}{ll}
\diamond \text { LSQ } & -\square \text { MC } \\
\triangleleft \text { ME } & -\circ \text { MI }
\end{array}
$$

FIGURE 20: Average variation of Flick roundness measurements at different CMM strategies.

(ii) averaged percentage errors as a function of the fitting algorithm response with respect to the global mean value are $100.31,99.48,100.73$, and $99.83 \%$ which are corresponding to LSQ, ME, MC, and MI, respectively. Quality of measurements indicates that LSQ and MC algorithms have about $0.31 \%$ and $0.73 \%$ inaccuracy, while the ME algorithm has accurate responses with the error range of $0.52 \%$.

(iii) signal measured for evaluated test samples at probe scanning speeds from 1 to $5 \mathrm{~mm} / \mathrm{s}$ (with $1 \mathrm{~mm} / \mathrm{s}$ interval value) has the standard deviation (SD) values of $1.3153,1.3065,1.3718,1.3255$ and $1.2903 \mathrm{~mm}$, respectively. It ensures that measurement at probe speed of $5 \mathrm{~mm} / \mathrm{s}$ is the suitable case for this work piece to satisfy the high level of accuracy.

(iv) the roundness standard deviation has significant variation at $3 \mathrm{~mm} / \mathrm{s}$ for all fitting algorithms; this may be due to probe response at resonance traveling speed.

(v) the LSQ and MC algorithms have the highest standard deviation average response, while the MI algorithm has accurate response within the application range.

(vi) the uncertainty due to repeatability in roundness measurement for four fitting algorithms lies between 0.0606 and 0.0335 . 
TABLE 4: Evaluation of uncertainty budget in roundness deviation measurements.

\begin{tabular}{|c|c|c|c|c|}
\hline CMM fitting algorithms & LSQ & $\mathrm{ME}$ & $\mathrm{MC}$ & MI \\
\hline Combined standards uncertainty, $u_{c}$ & 0.52650 & 0.52555 & 0.52650 & 0.523873 \\
\hline Expanded uncertainty $U_{\exp }$ & 1.0526 & 1.0511 & 1.0526 & 1.0478 \\
\hline Average of $U_{\exp }$ & \multicolumn{4}{|c|}{1.0510} \\
\hline
\end{tabular}

(vii) from the data presented in Figure 20, the values have been treated statistically using fourth order polynomial regression fit type to get general formulae of the roundness error (RON) in $\mu \mathrm{m}$ as a function of probe scanning speed $V$ for the different four fitting algorithms as follows:

$$
\begin{aligned}
\operatorname{RON}_{(M C)}= & 0.0708 V^{4}-0.9083 V^{3}+4.0292 V^{2} \\
& -7.0917 V+293.3000 \\
\operatorname{RON}_{(\mathrm{LSQ})}= & 0.0708 V^{4}-0.9083 V^{3}+4.0292 V^{2} \\
& -7.0917 V+292.7000 \\
\operatorname{RON}_{(M I)}= & 0.0167 V^{4}-0.2333 V^{3}+1.1333 V^{2} \\
& -2.2167 V+288.7000 ; \\
\operatorname{RON}_{(M E)} & 0.0500 V^{4}-0.6500 V^{3}+2.9500 V^{2} \\
& -5.3500 V+289.0000 .
\end{aligned}
$$

From polynomial regression equations (3), the empirical formulae illustrate that the MC and LSQ algorithms have high error potentials of 293.3 and $292.7 \mu \mathrm{m}$ to the probe scanning speed, where MI technique has the lowest error potential of $288.7 \mu \mathrm{m}$ at high sensitivity coefficients of -2.2 to the probe scanning speed $(V)$. The MC and LSQ algorithm have the same sensitivity coefficient of 4.0 to the probe scanning acceleration. The ME algorithm has an error potential of $289.0 \mu \mathrm{m}$ at sensitivity coefficients of -5.4 to the probe scanning speed and sensitivity coefficients of $3.0 \mu \mathrm{m}$ to the probe scanning acceleration.

4.3. Uncertainty Evaluation. In coordinate metrology, to measure the cylindrical artifact, as in our work, the measurement uncertainty mainly results from CMM machine, measurement environment, and sampling strategies [11]. Whilst the uncertainty influence of sampling strategy has not been considered here due to its complexity, while the uncertainty significant contributions include the following parameters.

4.3.1. Repeatability. The statistical study based on design of experiment was carried out in order to evaluate the expanded uncertainty in measurement. Statistical study of the repeatability in measurement has been calculated and evaluated for four fitting algorithms LSQ, ME, MC, and MI, which have the type $(\mathrm{A})$ uncertainty $\left(u_{1}\right)$ values of 0.0606 ,
$0.0537,0.0606$, and $0.0335 \mu \mathrm{m}$, respectively, as shown in Table 3.

4.3.2. Resolution. The resolution $r$ of CMM in last digit of a measured value, is causing an uncertainty component $u_{2}$ :

$$
u_{2}=\frac{r}{2 \sqrt{3}}=\frac{0.1}{2 \sqrt{3}}=0.0289 \mu \mathrm{m}
$$

4.3.3. Indication Error. The maximum permissible error of indication is $0.9 \mu \mathrm{m}$. When a normal distribution is assumed, the uncertainty component is

$$
u_{3}=\frac{0.9}{\sqrt{3}}=0.5196 \mu \mathrm{m}
$$

4.3.4. Temperature. The standard reference temperature for measurement is $20^{\circ} \mathrm{C}$. During the implementation, the environmental temperature in the coordinate metrology laboratory at NIS was controlled within $20 \pm 0.5^{\circ} \mathrm{C}$, the uncertainty component $u_{4}$ from temperature and dirt is estimated at $0.05 \mu \mathrm{m}$.

The previous components are all uncorrelated, so the uncertainties of measured points for roundness variation are calculated as follows:

$$
\begin{gathered}
u_{c}=\sqrt{u_{1}^{2}+u_{2}^{2}+u_{3}^{2}+u_{4}^{2}}, \\
U_{\exp }=K\left(u_{c}\right) .
\end{gathered}
$$

Eventually, the evaluation of uncertainties in this work reflects confidence in the high credibility of the proposed measurement method as shown obviously in Table 4. Thus, the author can say that the MI fitting technique is closer to reality and very much more accurate than the other techniques. In addition, the evaluation results illustrate that the LSQ and MC algorithms have higher uncertainties of $1.0526 \mu \mathrm{m}$, where MI technique has the lowest uncertainties of $1.0478 \mu \mathrm{m}$.

\section{Conclusions}

This paper presents new experimental investigations to improve the measurement accuracy of dimension and roundness form of a coordinate measuring machine for particular measurement tasks. The proposed method is very important in the development issue of CMMs dynamic verification to be more accurate and precise machines in measurement. Some error formulae of two main data sets have been postulated to correlate the diameter and roundness measurements within 
the application range. The method proposed requires just two selections of geometric fitting algorithms and probe scanning speeds in cylindrical measurements. From this research to improve dimension and roundness measurements quality, some conclusions can be drawn as follows:

(i) the investigation of dimension and form deviation using Flick standard may new suitable use as a high sensitive verification method for CMM performance [5];

(ii) suitable scanning speed of the machine touch probe should be well selected in accordance with the fitting algorithm to get high response quality with accurate dimension and roundness measurements;

(iii) for diameter and roundness measurements, MI algorithm shows lowest error potential as an indication to high quality response;

(iv) for diameter measurement both treatment algorithms ensure stable measuring accuracy at all probe scan speeds. This is probably due to the geometric perfection resonance of the circular surface of the Flick standard;

(v) for roundness measurement, both geometric fitting treatment algorithms ensure high measuring accuracy at $2 \mathrm{~mm} / \mathrm{s}$ probe scan speed may be due to probe design resonance;

(vi) for similar diameter measurements, MI algorithm show high quality response, while other algorithms show low quality response to the probe scanning speed;

(vii) for similar roundness measurements, $\mathrm{ME}$ algorithm show high quality response beside MC algorithm show low quality response to the probe scanning speed;

(viii) the expanded uncertainty result has been evaluated within $1.051 \mu \mathrm{m}$, which was less than the maximum limit of the CMM permissible probing error $(1.9 \mu \mathrm{m})$, confirming the high degree of confidence in the measurement results. Thus, the Flick standard may use as a simple reliable artifact for CMM evaluation;

(ix) from the investigations analysis, the author observed that there are proportional relationship between each of uncertainty and error potential of the empirical error formulae in measurement, Thus, the LSQ and $\mathrm{MC}$ algorithms have higher uncertainties which agreed with the higher rate of there error potentials, where MI technique has a lowest uncertainty of $1.0478 \mu \mathrm{m}$ that agreed with the lowest rate of their error potential;

(x) using a Flick standard should be practical high precision incremental in dimension (diameter) and roundness form indicator with high stability in measurement. This means a better transfer stability of CMM quality could be significantly improved;

(xi) eventually, the most basic measuring applications, the metrology of supplemental Flick standard, will increase the knowledge about the state of CMM measuring strategies.

\section{Conflict of Interests}

The authors declare that there is no conflict of interests regarding the publication of this paper.

\section{References}

[1] J. Buajarern, T. Somthong, S. H. R. Ali, and A. Tonmeuanwai, "Effect of step number on roundness determination using multi-step method," International Journal of Precision Engineering and Manufacturing, vol. 14, no. 11, pp. 2047-2050, 2013.

[2] S. H. R. Ali, H. H. Mohamed, and M. K. Bedewy, "Identifying cylinder liner wear using precise coordinate measurements," International Journal of Precision Engineering and Manufacturing, vol. 10, no. 5, pp. 19-25, 2009.

[3] I. Vrba, R. Palenčar, M. Hadžistević, B. Štrbac, and J. Hodolič, "The influence of the sampling strategy and the evaluation method on the cylindricity error on a coordinate measurement machine," Journal of Production Engineering, vol. 16, no. 2, 2013.

[4] S. H. R. Ali and J. Buajarerm, "New measurement method and uncertainty estimation for plate dimensions and surface quality," Advances in Materials Science and Engineering, vol. 2013, Article ID 918380, 10 pages, 2013.

[5] H. Nouira and P. Bourdet, "Evaluation of roundness error using a new method based on a small displacement screw," Measurement Science and Technology, vol. 25, no. 4, 2014.

[6] International Standard Organization, ISO/IEC Guide 98-3:2008, Uncertainty of Measurement-Part 3: Guide to the Expression of Uncertainty in Measurement, GUM, 1995.

[7] International Standard Organization: Geometrical Product Specifications (GPS), "Acceptance and reverification tests for Coordinate Measuring Machines (CMM)-Part 2: CMMs used for Measuring Size," ISO 10360-2, 2nd ed, 2001.

[8] International Standard Organization, Geometrical Product Specifications (GPS)-Acceptance and Reverification Tests for Coordinate Measuring Machines (CMM)_Part 4: CMMs Used in Scanning Measuring Mode, ISO 10360-4, 2nd edition, 2000.

[9] S. H. R. Ali, "Probing system characteristics in coordinate metrology," Measurement Science Review, vol. 10, no. 4, pp. 120 $129,2010$.

[10] H. S. Nielsen and M. C. Malburg, "Traceability and correlation in roundness measurement," Precision Engineering, vol. 19, no. 2-3, pp. 175-179, 1996.

[11] X. Wen, Y. Xu, H. Li, F. Wang, and D. Sheng, "Monte Carlo method for the uncertainty evaluation of spatial straightness error based on new generation geometrical product specification," Chinese Journal of Mechanical Engineering, vol. 25, no. 5, pp. 875-881, 2012. 

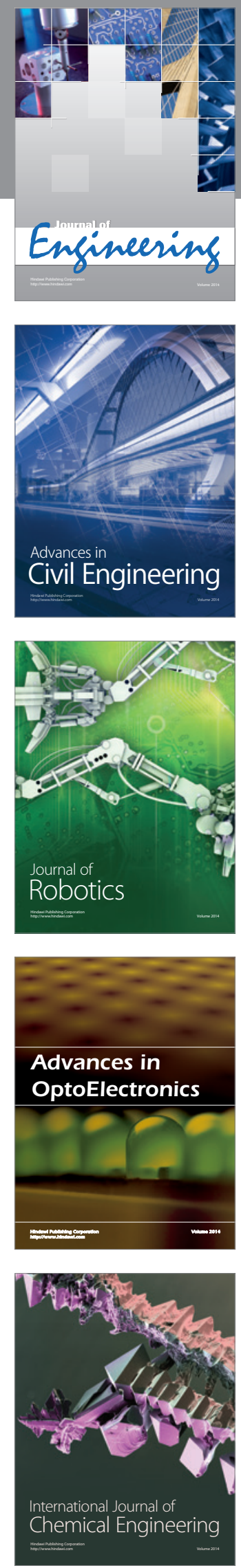

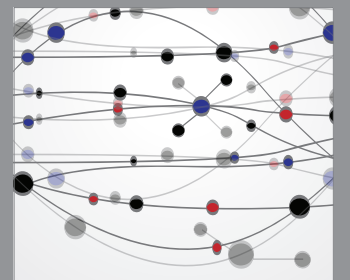

The Scientific World Journal
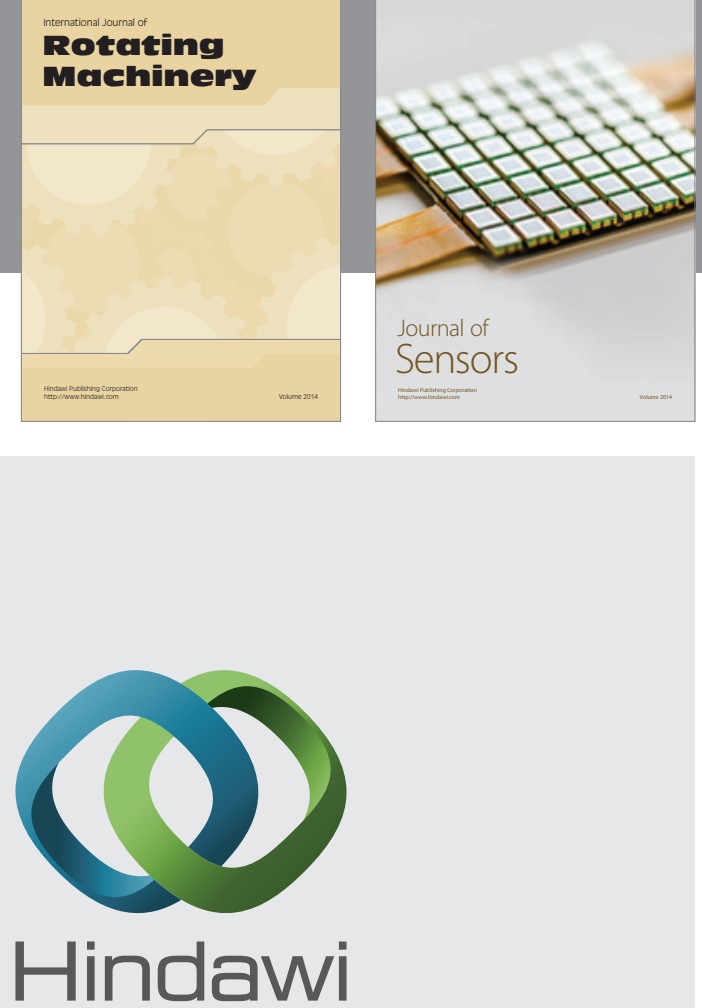

Submit your manuscripts at http://www.hindawi.com
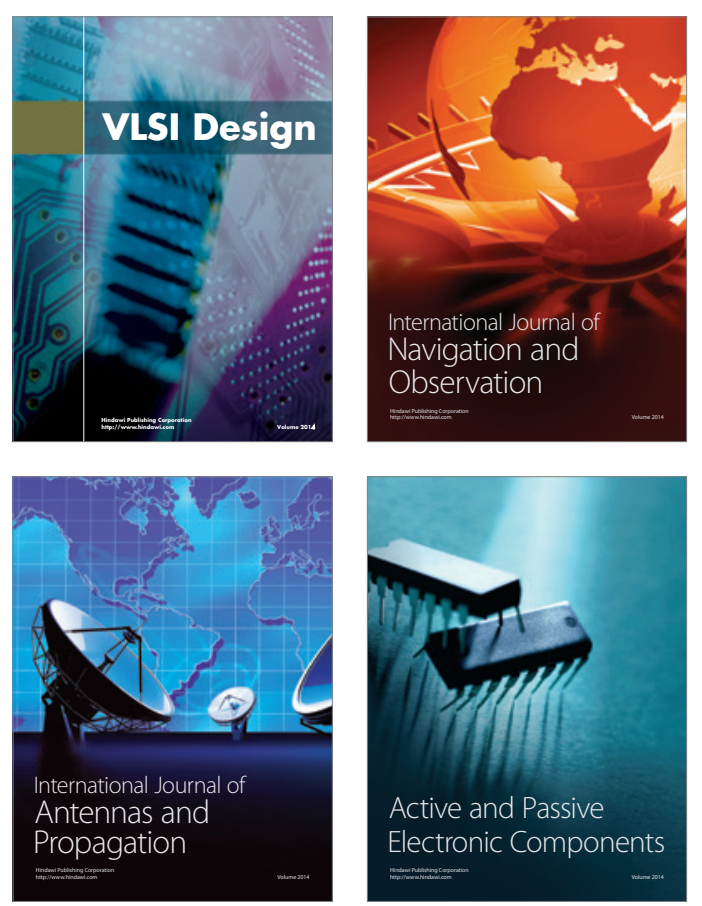
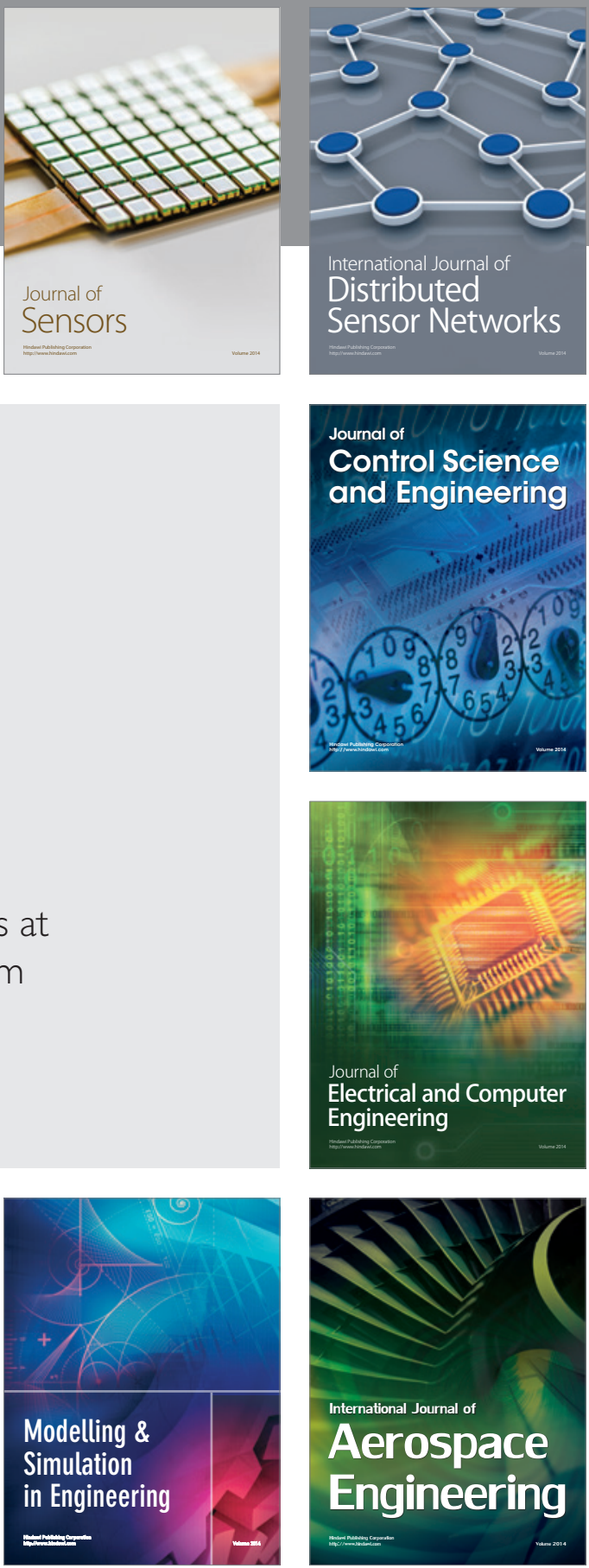

Journal of

Control Science

and Engineering
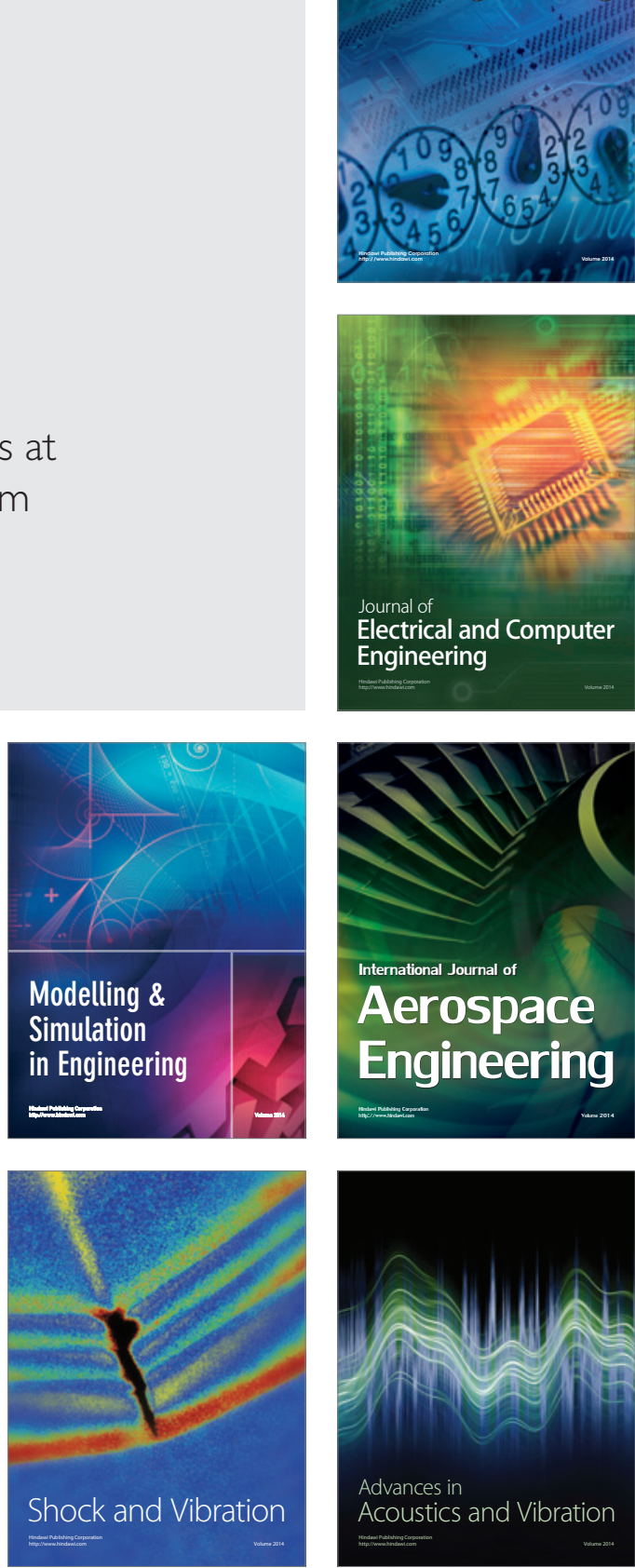